\title{
The Importance of Spiritual Consumption, Religious Expression and Subjective Well-Being among Christians in the US during COVID-19
}

\author{
Osnat Roth-Cohen ${ }^{1}$ (D) Sidharth Muralidharan ${ }^{2}$ D $\cdot$ Carrie La Ferle $^{3}$ (D)
}

Accepted: 17 January 2022 / Published online: 15 February 2022

(C) The Author(s), under exclusive licence to Springer Science+Business Media, LLC, part of Springer Nature 2022

\begin{abstract}
Uncertainty, fear, and distress have become prevalent in the lives of U.S. residents since the beginning of the COVID-19 pandemic. The unpredictable reality of social distancing, shutdowns, and isolation have affected daily routines and influenced well-being and health. Drawing on consumer culture theory, we conducted an exploratory study to examine the mediating role of consumer spirituality in the subjective well-being of religious Christians during COVID-19 and to discover links between well-being and health outcomes. Participants from the United States $(n=104)$ were recruited via a Qualtrics' online panel. Findings show that religiosity among Christians enhanced subjective well-being, demonstrating the positive effect of religious beliefs, especially during the COVID-19 pandemic. However, spiritual consumption mediated this relationship, suggesting the importance of possessions to religious expression and subjective well-being. Implications for messaging about health and well-being are discussed.
\end{abstract}

Keywords Religiosity $\cdot$ Subjective well-being $\cdot$ Consumer spirituality $\cdot$ Health messaging $\cdot$ COVID-19 $\cdot$ United States

Osnat Roth-Cohen

osnatrc@ariel.ac.il

Sidharth Muralidharan

sidmurali@smu.edu

Carrie La Ferle

laferle@smu.edu

1 School of Communication, Ariel University, Kyriat Hamada, 40700 Ariel, Israel

2 Temerlin Advertising Institute, Southern Methodist University, P.O. Box 750113, Dallas, TX 75275, USA

3 Marriott Endowed Professor of Ethics \& Culture, Temerlin Advertising Institute, Southern Methodist University, P.O. Box 750113, Dallas, TX 75275, USA 


\section{Introduction}

When people experience troubled times, they look to various outlets for comfort and security. According to previous findings about health and psychology, these outlets include consuming food, liquor, or other substances, exercising, shopping, and passing time with video games or television (Davies, 2017). Others turn for comfort to the stability of friends, family, and religion (Bentzen, 2020).

As COVID-19 has become a virtually inseparable part of our lives, people have become more concerned about the uncertainty surrounding their mental and physical health. Even early discussions about possible vaccines and their side-effects raised more questions than answers, evoking fear and distress. The unpredictable reality of illness, death, social distancing, and frequent shutdowns of basic services have influenced well-being and health.

Previous findings suggest that higher life satisfaction relates to better mental and physical health and better cognitive and social functioning (Batthyany \& RussoNetzer, 2014; Trzebiński et al., 2020). The pandemic has had a negative impact on life satisfaction (Rababa et al., 2021; Rigoli, 2021), leaving people searching for meaning and reconnecting with religion and their inner selves, a phenomenon known as "quest culture" (Roof, 2001, p. 46). In particular, religion has become a major coping mechanism (Bentzen, 2019, 2020; Simkin, 2020).

Consuming products or services can also provide an enlightening or spiritual experience (Belk et al., 1989), a phenomenon known as "consumer" spirituality (Husemann \& Eckhardt, 2018). Using consumer culture theory (Arnould \& Thompson, 2005), we set out to explore the role of religion in subjective well-being (SWB) during the COVID-19 pandemic and the role of consumer spirituality in this relationship.

This exploratory study is important for two reasons. First, our discussion of the effects of religiosity and consumer spirituality on SWB during an ongoing global health crisis is timely. Religious and spiritual institutions looking to reach constituents during the pandemic or future crises can use our findings to develop effective messages for target audiences.

As SWB can improve health and longevity (Diener et al., 2017), the findings can also help health institutions conveying health message to the religious by highlighting the importance of religiosity and consumer spirituality. For example, effective health messaging could emphasize how prayer and God might improve SWB among the religious.

Second, empirical studies about consumer spirituality as a construct for health messaging are scarce (Mathras et al., 2016). Scholars tend to position consumption as a behavior at odds with religious beliefs, even claiming that materialism runs counter to SWB. In the consumer-driven culture of the twenty-first century, this perspective might no longer be valid. To address these issues, we explored how consuming products might have spiritual utility for the highly religious and, in turn, enhance perceived well-being. The findings advance research about health communication, SWB, and the social and psychological impact of religious beliefs. 


\section{Literature Review}

\section{Religion and Subjective Well-Being}

Religion is a directed and active search for a sacred universal truth (Kim-Prieto \& Miller, 2018). Rinallo, Scott, et al. (2013), Rinallo, Borghini, et al. (2013)) considered religion "community-oriented, formalized, organized, and consisting of an organized system of beliefs, practices, and rituals designed to facilitate closeness to God" (p. 3). During times of crisis or adversity caused by disasters, people turn to religion, as it offers comfort and explanation (Bentzen, 2020). Unpredictable health disasters (e.g., COVID-19) intensify the use of religion compared to more predictable events (Belloc et al., 2016). A sense of connection with a higher power is an effective way to uphold a positive evaluation of one's life (Villani et al., 2019) and positively relates to SWB.

SWB is a measure of how people evaluate their lives. It includes both reflective cognitive judgments (e.g., overall life satisfaction) and emotional responses (Diener et al., 2018) that ultimately affect health and longevity. Multiple factors influence SWB, including the society in which a person lives, social relationships, and religiosity (Ellison et al., 1989).

Religiosity is the level of identification a person has with a religion and can be measured using behavioral items (e.g., attending church) and factors related to its impact on identity (Deaux et al., 1995).

Also relevant to the link between religion and SWB is the concept of resilience, which is emotional strength and the ability to respond to challenging situations in an effective way. Resilience is the "process of harnessing biological, psychosocial, structural, and cultural resources to sustain wellbeing" (Panter-Brick \& Leckman, 2013, p. 333). DeNisco (2011) defined resilience as "the ability to achieve, retain, or regain a level of physical or emotional health after devastating illness or loss" (p. 105).

Religion represents significant resilience factors for people enduring extreme difficulty (Pargament \& Cummings, 2010), such as the COVID-19 pandemic. Previous findings show that religious involvement reduced mortality rates (Hummer et al., 1999), protected against threats of illness (George et al., 2002), and decreased the probability of loneliness, misery, and anxiety (Rote et al., 2013). Scholars have found that religion promoted adaptive worldviews and coping strategies that improve mental health (Pargament \& Park, 1995; Manning \& Miles, 2018); therefore, religion can promote resilience during crises (e.g., global health pandemic).

Several ideas explain why life satisfaction might have decreased during COVID-19 (Zacher \& Rudolph, 2021). The first is the rate of the pandemic spread and its consequences; at the time of the current study, the United States had the world's highest death toll at 431,392 (1,303 deaths per 1 million people) (Worldometer, 2021). Second, to prevent the spread of the virus, the U.S. government enforced strict limitations, including full lockdowns and closures of businesses, restaurants, and educational systems, social distancing (even among 
families and during holidays), and isolation of infected and at-risk populations, increasing feelings of uncertainty and loneliness among citizens (Qiu et al., 2020; Van Bavel et al., 2020).

Third, the pandemic has upended churchgoing like never before; more than half of U.S. adults have adopted online worship to replace in-person church attendance (Pew Research Center, 2020). Finally, people have experienced mental tension in the form of health-related worry (Papadopoulos et al., 2021), job insecurity, and work-family conflict (Blustein et al., 2020; Rudolph et al., 2020). Under these conditions, SWB is likely to suffer.

Previous findings support the positive relationship between religion and SWB (e.g., Koenig \& Larson, 2001; Myers, 2000; Ng \& Fisher, 2016; Ramsay et al., 2019). Positive relationships have emerged between religious commitment and life satisfaction and between religious affiliation and life satisfaction (Ellison et al., 1989; Hadaway \& Roof, 1978). Using religious satisfaction measures, Poloma and Pendleton (1990) found a positive relationship between general life satisfaction and overall happiness.

Previous findings also indicate that in stressful times, individuals tend to turn to religion for support, as it is considered a positive force for mental health (Simkin, 2020). This positive correlation is consistent across SWB and religiosity studies. For example, Hadaway and Roof (1978) found that high religious commitment corresponded to high SWB. Weinstein et al. (1988) found that high religious faith strengthened the conviction to live a meaningful life.

The relationship appears to hold across multiple situations, religions, and cultures. Scholars examining this effect across Jewish participants similarly found that religion positively predicted SWB. For example, trust in God related to greater happiness and lower levels of anxiety and depression among Jewish participants (Rosmarin et al., 2009). Similarly, in a study in Indonesia about materialism, religiosity, and status consumption on SWB among a Muslim population, Budiman and O'Cass (2007) found that religiosity had a positive effect on SWB.

Based on previous findings, we predict a similar relationship to exist where people with higher levels of religiosity will also have higher levels of subjective well-being. However, it is important to test the relationship in the current study as religious attendance has changed during the pandemic, shifting to online for many, while the context of the environment given the pandemic has also altered regular lifestyle patterns.

Within this context, nothing can be assumed, particularly with the goals of this study to test the mediating construct of consumer spirituality. Though the relationship between religiosity and SWB has been confirmed in past research, it is important to test under present pandemic conditions.

H1 Religiosity will have a positive impact on SWB.

\section{Mediating Effect of Consumer Spirituality on Subjective Well-Being}

The COVID-19 pandemic has shifted consumption patterns. According to a McKinsey Report, the pandemic has led to surges in e-commerce, preference for digital entertainment, and focus on health and hygiene (Kohli et al., 2020). 
Religious institutions have also moved online, recording or streaming services so that members can watch on a screen from home, resulting in a deeper faith (Gecewicz, 2020). With religiosity growing and online consumption on the rise, the intersection of religion and consumption has become even more intriguing.

Previous findings suggest that material possessions negatively relate to religiosity and SWB (Clavier, 2019; LaBarbera \& Gurhan, 1997; Richins \& Dawson, 1992). Materialism, which focuses primarily on self-benefits, tends to contradict religious beliefs and lead to unhappiness, greed, selfishness, and envy. However, viewed in the context of spirituality (i.e., consumption to achieve spiritual goals), materialism might enhance SWB. According to a Pew study, many religious Americans have adopted "new-age" beliefs (e.g., reincarnation, astrology, psychics, and presence of spiritual energy in nature; Gecewicz, 2018).

Furthermore, eight in ten religious Americans believe in God, while six in ten have new-age beliefs. Though previous findings distinguish between religion and spirituality as separate constructs that differentially influence personality traits, scholars still consider spirituality the core of any religion and, thus, see the two concepts as inextricably linked (Gupta \& Sharma, 2018).

Recontextualizing consumption, we posited that it might act as a bridge between religion and SWB. Muniz and Schau (2005) explained how religion is an enduring creation of humanity and is fundamental to human existence. They also suggested that the meaningfulness that people associate with material objects is fundamental and that, in today's market-driven capitalist society, brands (e.g., religious organizations) are part of the fabric of society and people's identities. Spiritually driven consumption among the religious is an important way to facilitate consumer spirituality (Rinallo, Borghini, et al., 2013; Rinallo, Scott, et al., 2013).

Consumer spirituality consists of the interrelated practices and processes in which people engage when consuming products, services, and places that have "spiritual utility" (Kale, 2006, p. 108). That is, market offerings that target consumer spirituality quench the thirst for meaningful encounters with one's inner self or a higher external power (Husemann \& Eckhardt, 2019). Spirituality has embraced capitalism to a greater degree than religion (Gupta \& Sharma, 2018), and many people look for spiritually transforming experiences that influence consumer behavior, demonstrating the idea of the spiritual supermarket (Kotler, 2019). Spirituality is the meaningful exploration of the inner self in relation to external reality (Kale, 2006), giving people meaning and a sense of purpose (Le et al., 2019).

However, in the current study, we focused on consumer spirituality and explored whether it might positively bridge the relationship between religiosity and SWB, particularly in the reality of our 21 st-century consumer culture.

Arnould and Thompson (2005) defined consumer culture as "an interconnected system of commercially produced images, texts, and objects that groups usethrough the construction of overlapping and even conflicting practices, identities, and meanings - to make collective sense of their environments and to orient their members' experiences and lives" (p. 869). The practice of orienting members is not solely for traditional products and services; even religious organizations participate in branding (Jones, 2004). 
Consumer culture theory (Arnould \& Thompson, 2005) can help explain how consumers actively participate in the development, maintenance, and altering of their identities and goals. Consumers construct their lives through their purchases and the symbolic images of goods, brands, and advertisements associated with their purchases. Consumer culture theory supports the idea of resilience through spiritual consumption, one of various strategies for coping with the uncertainties of the pandemic. In other words, resilience in response to COVID-19 primarily targets recovery of personal well-being (Trenz, Heft, Vaughan \& Pfetsch, 2021), a goal that people might achieve through spiritual consumption.

Consumer spirituality includes (a) the process through which consumers increasingly desire to access a marketplace that promises transcendence and (b) the idea that spirituality is something that people can consume (Husemann \& Eckhardt, 2019). For example, a highly religious Christian might purchase a ring engraved with the word "faith." This purchase, while material, might provide a symbol of a sacred possession (Belk et al., 1989), enhancing both identification with a religious group and SWB. Ellison et al. (1989) found that devotional intensity, measured by frequency of prayer and feelings of closeness to God, had a positive impact on SWB (Fig. 1).

We predicted that possessions related to one's religion might enhance feelings of closeness to God for religious individuals, thereby enhancing SWB and health. Based on these ideas, we posited the following hypothesis:

H2 Consumer spirituality will mediate the positive impact of religiosity on SWB.

\section{Method}

Qualtrics maintains a network of online panel providers who supply quality respondents for market research. Panel providers continually update the demographic and psychographic attributes of their members. Qualtrics sends the online survey link to multiple providers, who randomly assign members, according to client needs, from their respective panels, and sends e-mail invitations to solicit participation. The invitation highlights that the survey is for research purposes only, includes the period of the study and incentives for participation, and does not mention the specific research objectives of the survey, minimizing self-selection bias. Members may withdraw from the study at any time.



Fig. 1 Hypothesized Model 
Using religion as the primary filter, we recruited U.S. Christians $(n=104)$ via Qualtrics' online panels during the period of September 11-14, 2020. The small sample size (i.e., between 20 and 150 respondents) was appropriate for the exploratory nature of the study (Daniel, 2012). Respondents began the survey after giving informed consent to the approved study (ref H20-125-MURS). Respondents answered questions regarding their religiosity, consumer spirituality, SWB, and demographic information and received compensation for their participation. Table 1 presents the demographic profiles of the participants.

Table 1 Demographic Profile

\begin{tabular}{|c|c|c|}
\hline & $\mathrm{M}$ & SD \\
\hline \multirow[t]{2}{*}{ Age } & 38.25 & 13.99 \\
\hline & $n$ & $\%$ \\
\hline \multicolumn{3}{|l|}{ Religion } \\
\hline Christians & 104 & 100 \\
\hline \multicolumn{3}{|l|}{ Gender } \\
\hline Male & 50 & 48.1 \\
\hline Female & 54 & 51.9 \\
\hline \multicolumn{3}{|l|}{ Education } \\
\hline No high school & 4 & 3.8 \\
\hline High school & 33 & 31.7 \\
\hline Two-year college (associate) & 20 & 19.2 \\
\hline Four-year college (bachelor) & 29 & 27.9 \\
\hline Masters & 10 & 9.6 \\
\hline Doctoral & 2 & 1.9 \\
\hline Professional & 6 & 5.8 \\
\hline \multicolumn{3}{|l|}{ Family Household Income } \\
\hline Less than $\$ 10,000$ & 11 & 10.6 \\
\hline$\$ 10,000-\$ 14,999$ & 6 & 5.8 \\
\hline$\$ 15,000-\$ 24,999$ & 13 & 12.5 \\
\hline$\$ 25,000-\$ 34,999$ & 15 & 14.4 \\
\hline$\$ 35,000 — \$ 49,999$ & 10 & 9.6 \\
\hline$\$ 50,000 — \$ 74,999$ & 16 & 15.4 \\
\hline$\$ 75,000-\$ 99,999$ & 13 & 12.5 \\
\hline$\$ 100,000-\$ 149,999$ & 11 & 10.6 \\
\hline$\$ 150,000-\$ 199,999$ & 3 & 2.9 \\
\hline$\$ 200,000$ or higher & 6 & 5.8 \\
\hline \multicolumn{3}{|l|}{ Ethnicity } \\
\hline African-American & 22 & 21.2 \\
\hline American Indian or Alaska Native & 1 & 1.0 \\
\hline Asian or Asian American & 6 & 5.8 \\
\hline White or Caucasian & 67 & 64.4 \\
\hline Hispanic or Latino & 6 & 5.8 \\
\hline Multiracial & 2 & 1.9 \\
\hline
\end{tabular}




\section{Measures}

Religiosity (Putney \& Middleton, 1961) was measured on a six-point Likert scale ( $1=$ strongly disagree, $6=$ strongly agree). We developed the consumer spirituality construct for the current study using the spirituality scale of Delaney (2005) and the consumer spirituality scale of Narang (2013). Items were measured on a six-point Likert scale ( $1=$ strongly disagree, $6=$ strongly agree $)$.

SWB (Brinkerhoff \& Jacob, 1986) was measured on a six-point semantic differential scale using items that described how respondents felt about the current conditions of their life. Confirmatory factor analysis (CFA) reveals that the full model had good fit $\left(\chi^{2}(186)=321.67, p<0.001\right.$; TLI $=0.921$; CFI $=0.930$, RMSEA $=0.084)$. Table 2 presents CFI and RMSEA scores for each scale. By assessing McDonald's Omega (Hayes \& Coutts, 2020) and ordinal coefficient

Table 2 Confirmatory Factor Analysis and Scale Reliability

\begin{tabular}{|c|c|c|c|c|}
\hline Factor items & CFI & RMSEA & $\omega$ & $\alpha$ \\
\hline Overall Model Fit & .930 & .084 & & \\
\hline Subjective Well-Being & .911 & .167 & .952 & .965 \\
\hline \multicolumn{5}{|l|}{ Doesn't give me much chance-brings out the best in me } \\
\hline \multicolumn{5}{|l|}{ Lonely-friendly } \\
\hline \multicolumn{5}{|l|}{ Disappointing-rewarding } \\
\hline \multicolumn{5}{|l|}{ Discouraging-hopeful } \\
\hline \multicolumn{5}{|l|}{ Empty-full } \\
\hline \multicolumn{5}{|l|}{ Miserable-enjoyable } \\
\hline \multicolumn{5}{|l|}{ Worried-calm } \\
\hline \multicolumn{5}{|l|}{ Useless-worthwhile } \\
\hline \multicolumn{5}{|l|}{ Boring-interesting } \\
\hline Consumer Spirituality & .973 & .125 & .943 & .894 \\
\hline \multicolumn{5}{|l|}{$\begin{array}{l}\text { The products/services I buy and use, helps me gain access to my inner } \\
\text { spirit }\end{array}$} \\
\hline \multicolumn{5}{|l|}{$\begin{array}{l}\text { My purchase efforts are directed toward understanding the purpose and } \\
\text { meaning of life }\end{array}$} \\
\hline \multicolumn{5}{|l|}{ The products/services I buy and use, helps me connect to the universe } \\
\hline \multicolumn{5}{|l|}{ The products/services I buy and use, provides me with a sense of purpose } \\
\hline \multicolumn{5}{|l|}{ My purchases are aligned with my philosophy of life } \\
\hline \multicolumn{5}{|l|}{ I buy and use products/services to fulfill my spiritual needs } \\
\hline Religiosity & .994 & .052 & .923 & .858 \\
\hline \multicolumn{5}{|l|}{ Religious values are more important than material things } \\
\hline \multicolumn{5}{|l|}{ I believe in God } \\
\hline \multicolumn{5}{|l|}{ My religion is very important to me } \\
\hline \multicolumn{5}{|l|}{ If people were more religious, this would be a better world } \\
\hline \multicolumn{5}{|l|}{ I am very religious } \\
\hline I pray regularly & & & & \\
\hline
\end{tabular}


alpha (Dunn, Bauley, \& Brunsden, 2014), we found that the scales were highly reliable (see Table 2).

\section{Main Analysis}

Preliminary analyses were conducted to explore the relationships among the variables of study. Correlations showed that religiosity positively related to consumer spirituality $(r(102)=0.42, p<0.001)$, while religiosity $(r(102)=0.41, p<0.001)$ and consumer spirituality $(r(102)=0.46, p<0.001)$ positively related to SWB. Furthermore, with an absence of multicollinearity, the data supported religiosity and consumer spirituality as distinct constructs (Tolerance $=0.823$ ). (Field, 2005). We then used the resulting variables in the mediation analyses.

To test the main hypotheses, we used Model 4 of the PROCESS macro and a bootstrapping procedure with 5000 samples (Hayes, 2017). Religiosity was the independent variable, consumer spirituality was the mediator, and SWB was the dependent variable. Findings show that religiosity had a positive impact on consumer spirituality $(B=0.46, \mathrm{SE}=0.09, p<0.001)$. Both religiosity $(B=0.26, \mathrm{SE}=0.09$, $p<0.01)$ and consumer spirituality $(B=0.30, \mathrm{SE}=0.08, p<0.001)$ had a positive impact on SWB. Consumer spirituality mediated the effect of religiosity on SWB $(B=0.14, \mathrm{SE}=0.06,95 \% \mathrm{CI}=0.0492$ to 0.2718$)$. Based on the results, $\mathrm{H} 1$ and $\mathrm{H} 2$ were supported.

\section{Discussion}

COVID-19 has disrupted the lives of many, and religion has become a major coping mechanism (Bentzen, 2019, 2020; Simkin, 2020). Using consumer culture theory, we explored whether religiosity improved SWB among the religious during the pandemic. More importantly, we examined the mediating effect of consumer spirituality on this relationship.

Christian religiosity enhanced SWB, showing that religious beliefs and rituals can increase certainty and happiness. This finding illustrates that the religious look to a divine presence for help with challenging life events (Gorsuch \& Smith, 1983). Religion also represents significant resilience factors for people facing extreme difficulty in life (Pargament \& Cummings, 2010), such as the COVID-19 pandemic. People are likely to turn to religion when confronting health difficulties (Pargament \& Hahn, 1986), for religion is an effective way to maintain a positive evaluation of one's life (Villani et al., 2019).

Previous findings indicate that materialism is at odds with religious beliefs and values (Clavier, 2019; LaBarbera \& Gurhan, 1997; Richins \& Dawson, 1992). However, the current findings show that placing consumption in the context of attaining spiritual goals can reveal an otherwise hidden congruence between these two concepts. Consumer spirituality played a significant mediating role in enhancing SWB. Christians with strong religiosity can experience spirituality through product or service consumption, enhancing SWB and improving their health. Consumer 
culture theory (Arnould \& Thompson, 2005) helps explain why religious Christians, in order to achieve a fulfilling life, not only embraced God and prayer but were also open to experiencing spirituality through consumption.

The lockdowns and social distancing imposed by the global health crisis, along with the dramatic shift in digital media usage for social and work connections, might have driven people to seek and express internal satisfaction and self-fulfillment through products, services, and experiences (Kelemen \& Peltonen, 2005). Religiosity influences the manner in which consumers evaluate goods and services and appears to complement a consumer-centered world. According to Muniz and Schau (2005), "it responds to social, cultural, and market forces. It adapts, but it leaves its explanatory mythologies in all sorts of places, including the marketplace and brands" (p. 746).

Individuals have experienced sacredness while shopping and consuming (Belk et al., 1989). Their purchases shape their lives and the associated symbolic images of material goods can increase life satisfaction and well-being as they construct their religious identities through sacred possessions (Belk et al., 1989). Our findings shed new light on the relationship between religiosity and consumer spirituality, demonstrating that sacralized goods can also enhance SWB.

The findings provide crucial insight into effective health messaging. Based on the idea that spirituality is the core of any religion (Gupta \& Sharma, 2018), congruency theory can help explain the relationship between religiosity and consumer spirituality. Congruency theory posits "changes in evaluation are always in the direction of increased congruity with the existing frame of reference" (Osgood \& Tannenbaum, 1955 , p. 43). When people receive information, including communication messages (e.g., advertisements), they use existing attitudes to process the relevancy and consistency of the information, experiencing how the information fits into their existing schema (Misra \& Beatty, 1990). Messages congruent with self-perceptions are generally more effective than incongruent messages (Chang, 2002; Uskul \& Oyserman, 2010).

An incongruent message, one that clashes with existing beliefs, will surprise receivers and might create unwanted tension. The current findings align with congruence theory (Osgood \& Tannenbaum, 1955), demonstrating fit and consistency between Christian religiosity and consumer spirituality. This relationship is also consistent with the strong consumer culture prevalent in the United States (Berger, 2015). Therefore, health messages about spiritual consumption that are congruent with religious beliefs can lead to favorable attitude toward the message and strengthen SWB.

The current findings have important managerial implications for religious institutions who are reaching out to current and potential members during the COVID19 pandemic and beyond. Religious institutions can use religiosity to segment their target market and reach out to their members by highlighting the importance of religiosity in their lives. Health messaging that emphasizes how prayer and God can help improve SWB might prove effective. Furthermore, both religious institutions and commercial brands in the United States can show how consuming products and services that offer spiritual utility or help fulfill the spiritual goals of meaning and purpose can improve SWB among the religious. 


\section{Limitations and Future Research}

Despite several important contributions to theory and practice, the current study has limitations. First, though the sample size was appropriate for the exploratory nature of the study (Daniel, 2012), we acknowledge the low power of this small sample for detecting effects. Second, there is an inability to assess causal inference due to the cross-sectional nature of the sample. Therefore, scholars should consider securing a larger sample size using longitudinal surveys to enhance generalizability. Third, being an online sample may attract only a certain group of people who may not be representative of Christians in general. Christianity features many denominations that might have differing perspectives on religion and consumer spirituality.

In addition to online surveys, scholars should consider applying the current model to a more diverse religious sample by analyzing participants through interviews and focus groups. Third, previous findings in COVID-19 research indicate that people across the world have become more religious (Bentzen, 2020); however, a decline in religiosity might occur once the pandemic subsides.

Scholars could test the robustness of the current model by conducting a followup study to determine whether the relationships between religiosity and consumer spirituality have shifted. Scholars could also apply the model to other religions (e.g., Judaism, Hinduism, Islam, and Buddhism). Finally, scholars could test different health messages by recruiting people with various levels of religiosity and using different consumer spirituality cues to assess varied influences on SWB.

\section{Conclusion}

This article outlines that religiosity among Christians enhanced their SWB, demonstrating the positive effect of religious beliefs, especially during the COVID-19 pandemic. More importantly, spiritual consumption mediated this relationship, suggesting the importance of goods to religious expression and SWB. Consuming commodities and services that offer spiritual value can improve SWB among the religious.

Religiosity and consumerism have often been perceived as having a contentious relationship. However, this study provides initial support for the fit between Christian religiosity and consumer spirituality, while highlighting insights related to effective health messaging. Health messages about spiritual consumption that are congruent with religious beliefs can lead to favorable attitudes toward the message and brand as well as strengthen SWB.

Acknowledgements We are grateful to have received funding from the following sources to help undertake this research: Ariel University Grants Program for COVID-19 Research (Israel), the Meadows School of the Arts, the Temerlin Advertising Institute, and the Marriott Family Endowed Professor Award at Southern Methodist University.

Funding The authors have no relevant financial or non-financial interests to disclose. 
Ethical approval The questionnaire and methodology for this study was approved by the Human Research Ethics committee of Southern Methodist University (Ethics approval number: H20-125-MURS).

Informed consent Informed consent was obtained from all individual participants included in the study.

\section{References}

Arnould, E. J., \& Thompson, C. J. (2005). Consumer culture theory (CCT): Twenty years of research. Journal of Consumer Research, 35(2), 868-882. https://doi.org/10.1086/591204

Batthyany, A., \& Russo-Netzer, P. (2014). Psychologies of meaning. In A. Batthyany \& P. Russo-Netzer (Eds.), Meaning in positive and existential psychology (pp. 3-22). Springer.

Belk, R. W., Wallendorf, M., \& Sherry, J. F. (1989). The sacred and the profane in consumer behavior: Theodicy on the odyssey. Journal of Consumer Research, 16(1), 1-38. https://doi.org/10.1086/ 209191

Belloc, M., Francesco, D., \& Galbiati, R. (2016). Earthquakes, religion, and transition to self-government in Italian cities. The Quarterly Journal of Economics, 131(4), 1875-1926. https://doi.org/10.1093/ qje/qjw020

Bentzen, J. S. (2020). In crisis, we pray: Religiosity and the COVID-19 pandemic. CEPR Discussion Paper Series, 52-108. Retrieved from In Crisis, We Pray: Religiosity and the COVID-19 Pandemic by Jeanet Bentzen : SSRN

Bentzen, J. S. (2019). Acts of God? Religiosity and natural disasters across subnational world districts. The Economic Journal, 129(622), 2295-2321. https://doi.org/10.1093/ej/uez008

Berger, A. A. (2015). Ads, fads and consumer culture: Advertising's impact on American character and society. Rowman and Littlefield.

Blustein, D. L., Duffy, R., Ferreira, J. A., Cohen-Scali, V., Cinamon, R. G., \& Allan, B. A. (2020). Unemployment in the time of COVID-19: A research agenda. Journal of Vocational Behavior, 119, 103436. https://doi.org/10.1016/j.jvb.2020.103436

Brinkerhoff, M., \& Jacob, J. C. (1986). Quality of life in an alternative lifestyle: The smallholding movement. Social Indicators Research, 18(2), 153-173. https://doi.org/10.1007/BF00317546

Budiman, A., \& O'Cass, A. (2007). Studying the effects of materialism, religiosity and status consumption on subjective well-being: An Indonesian perspective. Proceedings of the ANZMAC 2007 Conference. $\uparrow$

Chang, C. (2002). Self-congruency as a cue in different advertising-processing contexts. Communication Research, 29(5), 503-536. https://doi.org/10.1177/009365002236193

Clavier, M. (2019). On consumer culture identity: The church and the rhetorics of delight. Bloomsbury Publishing.

Daniel, J. (2012). Sampling essentials: Practical guidelines for making sampling choices. SAGE.

Davies, J. (2017). 10 negative coping mechanisms people use to hide from their problems. Learningmind.com. Retrieved from https://www.learning-mind.com/coping-mechanisms/

Deaux, K., Reid, A., Mizrahi, K., \& Ethier, K. A. (1995). Parameters of social identity. Journal of Personality and Social Psychology, 68(2), 280. https://doi.org/10.1037/0022-3514.68.2.280

Delaney, C. (2005). The spirituality scale: Development and psychometric of a holistic instrument to assess the human spiritual dimension. Journal of Holistic Nursing, 23(2), 145-167. https://doi.org/ $10.1177 / 0898010105276180$

DeNisco, S. (2011). Exploring the relationship between resilience and diabetes outcomes in African Americans. Journal of the American Academy of Nurse Practitioners, 23(11), 602-610. https://doi. org/10.1111/j.1745-7599.2011.00648.x

Diener, E., Oishi, S., \& Tay, L. (2018). Advances in subjective well-being research. Nature Human Behavior, 2(4), 253. https://doi.org/10.1038/s41562-018-0307-6

Diener, E., Pressman, S. D., Hunter, J., \& Delgadillo-Chase, D. (2017). If, why, and when subjective well-being influences health, and future needed research. Applied Psychology: Health and WellBeing, 9(2), 133-167. https://doi.org/10.1111/aphw.12090

Dunn, T. J., Baguley, T., \& Brunsden, V. (2014). From alpha to omega: A practical solution to the pervasive problem of internal consistency estimation. British Journal of Psychology, 105(3), 399-412. https://doi.org/10.1111/bjop.12046 
Ellison, C. G., Gay, D. A., \& Glass, T. A. (1989). Does religious commitment contribute to individual life satisfaction? Social Forces, 68(1), 100-123. https://doi.org/10.1093/sf/68.1.100

Field, A. (2005). Discovering statistics using SPSS. SAGE.

Gecewicz, C. (2018). 'New age' beliefs common among both religious and non-religious Americans. Pew Research Center. Retrieved from https://www.pewresearch.org/fact-tank/2018/10/01/new-age-belie fs-common-among-both-religious-and-nonreligious-americans/

Gecewicz, C. (2020). Few Americans say their house of worship is open, but a quarter say their faith has grown amid pandemic. Pew Research Center. Retrieved from https:/www.pewresearch.org/facttank/2020/04/30/few-americans-say-their-house-of-worship-is-open-but-a-quarter-say-their-relig ious-faith-has-grown-amid-pandemic/

George, L. K., Ellison, C. G., \& Larson, D. B. (2002). Explaining the relationships between religious involvement and health. Psychological Inquiry, 13(3), 190-200. https://doi.org/10.1207/S1532 7965PLI1303_04

Gorsuch, R. L., \& Smith, C. S. (1983). Attribution of responsibility to God: An interaction of religious beliefs and outcomes. Journal for the Scientific Study of Religion, 22(4), 340-352. https://doi.org/ $10.2307 / 1385772$

Gupta, N., \& Sharma, P. (2018). Spirituality and religiosity at the junction of consumerism: Exploring consumer preference for spiritual brands. International Journal of Consumer Studies, 42(6), 724735. https://doi.org/10.1111/ijcs. 12467

Hadaway, C. K., \& Roof, W. C. (1978). Religious commitment and the quality of life in American society. Review of Religious Research, 19(3), 295-307. https://doi.org/10.2307/3510129

Hayes, A. F. (2017). Introduction to mediation, moderation, and conditional process analysis: A regression-based approach. Guilford Publications.

Hayes, A. F., \& Coutts, J. J. (2020). Use omega rather than Cronbach's alpha for estimating reliability But... Communication Methods and Measures, 14(1), 1-24. https://doi.org/10.1080/19312458. 2020.1718629

Hummer, R. A., Rogers, R. G., Nam, C. B., \& Ellison, C. G. (1999). Religious involvement and US adult mortality. Demography, 36(2), 273-285. https://doi.org/10.2307/2648114

Husemann, K. C., \& Eckhardt, G. M. (2018). Consumer deceleration. Journal of Consumer Research, 45(6), 1142-1163. https://doi.org/10.1093/jcr/ucy047

Husemann, K. C., \& Eckhardt, G. M. (2019). Consumer spirituality. Journal of Marketing Management, 35(5-6), 391-406. https://doi.org/10.1080/0267257X.2019.1588558

Jones, M. (2004). Judaism, spirituality, and disability. Journal of Religion, Disability \& Health, 8(1-2), 55-88. https://doi.org/10.1300/J095v08n01_06

Kale, S. (2006). Consumer spirituality and marketing. In M. Craig, T. Lees, \& G. Gregory (Eds.), AsiaPacific advances in consumer research (pp. 108-110). Association for Consumer Research.

Kelemen, M., \& Peltonen, T. (2005). Spirituality: A way to an alternative subjectivity? Organization Management Journal, 2(1), 52-63. https://doi.org/10.1057/omj.2005.11

Kim-Prieto, C., \& Miller, L. (2018). Intersection of religion and subjective well-being. In E. Diener, S. Oishi, \& L. Tay (Eds.), Handbook of well-being. DEF Publishers.

Koenig, H. G., \& Larson, D. B. (2001). Religion and mental health: Evidence for an association. International Review of Psychiatry, 13(2), 67-78. https://doi.org/10.1080/09540260124661

Kohli, S., Timelin, B., Fabius, V., \& Veranen, S. M. (2020). How COVID-19 is changing consumer behavior - now and forever. McKinsey \& Company. Retrieved from https://www.mckinsey.com/ / media/mckinsey/industries/retail/our\%20insights/how\%20covid\%2019\%20is\%20changing\%20con sumer\%20behavior\%20now\%20and\%20forever/how-covid-19-is-changing-consumer-behaviornowand-forever.pdf

Kotler, P. (2019). The market for transformation. Journal of Marketing Management, 35(5-6), 407-409. https://doi.org/10.1080/0267257X.2019.1585713

Le, Y. K., Piedmont, R. L., \& Wilkins, T. A. (2019). Spirituality, religiousness, personality as predictors of stress and resilience among middle-aged Vietnameseborn American Catholics. Mental Health, Religion \& Culture, 22(7), 754-768.

Manning, L. K., \& Miles, A. (2018). Examining the effects of religious attendance on resilience for older adults. Journal of Religion and Health, 57(1), 191-208. https://doi.org/10.1007/s10943-017-0438-5

Mathras, D., Cohen, A. B., Mandel, N., \& Mick, D. G. (2016). The effects of religion on consumer behavior: A conceptual framework and research agenda. Journal of Consumer Psychology, 26(2), 298-311. https://doi.org/10.1016/j.jcps.2015.08.001 
Misra, S., \& Beatty, S. E. (1990). Celebrity spokesperson and brand congruence: An assessment of recall and affect. Journal of Business Research, 21(2), 159-173. https://doi.org/10.1016/0148-2963(90)90050-N

Muniz, M. A., Jr., \& Jensen Schau, H. (2005). Religiosity in the abandoned apple Newton brand community. Journal of Consumer Research, 31(4), 737-747. https://doi.org/10.1086/426607

Myers, D. G. (2000). The funds, friends, and faith of happy people. American Psychologist, 55(1), 56-67. https://doi.org/10.1037/0003-066X.55.1.56

Narang, R. (2013). Measuring consumer spirituality through a valid scale [Conference presentation]. Proceedings of the $3^{\text {rd }}$ biennial conference of the Indian Academy of Management. Retrieved from http:// vslir.iima.ac.in:8080/xmlui/bitstream/handle/11718/11492/CB-PP-322-Measuring_Consumer_Spiri tuality_through_a_valid_scale-68-Narang_b.pdf?sequence=1\&isAllowed=y

Ng, E. W., \& Fisher, A. T. (2016). Protestant spirituality and well-being of people in Hong Kong: The mediating role of sense of community. Applied Research in Quality of Life, 11(4), 1253-1267. https://doi. org/10.1007/s11482-015-9435-6

Osgood, C. E., \& Tannenbaum, P. H. (1955). The principle of congruity in the prediction of attitude change. Psychological Review, 62(1), 42-55. https://doi.org/10.1037/h0048153

Panter-Brick, C., \& Leckman, J. F. (2013). Editorial commentary: Resilience in child development-interconnected pathways to wellbeing. Journal of Child Psychology and Psychiatry, 54(4), 333-336. https:// doi.org/10.1111/jcpp. 12057

Papadopoulos, I., Lazzarino, R., Wright, S., Logan, P. E., \& Koulouglioti, C. (2021). Spiritual support during COVID-19 in England: A scoping study of online sources. Journal of Religion and Health, 60(4), 2209-2230. https://doi.org/10.1007/s10943-021-01254-1

Pargament, K., \& Cummings, J. (2010). Anchored by faith- religion as a resilience factor. In J. W. Reich, A. J. Zautra, \& J. S. Hall (Eds.), Handbook of adult resilience (pp. 193-210). The Guildford Press.

Pargament, K. L., \& Hahn, J. (1986). God and the just world: Causal and coping attributions to God in health situation. Journal for the Scientific Study of Religion, 25(2), 193-207. https://doi.org/10.2307/1385476

Pargament, K. I., \& Park, C. L. (1995). Merely a defense? The variety of religious means and ends. Journal of Social Issues, 51(2), 13-32. https://doi.org/10.1111/j.1540-4560.1995.tb01321.x

Pew Research Center (2020). Americans oppose religious exemptions from Coronavirus-related restrictions. Pew Research Center. Retrieved from https://www.pewforum.org/2020/08/07/americans-oppose-relig ious-exemptions-from-coronavirus-related-restrictions/

Poloma, M. M., \& Pendleton, B. F. (1990). Religious domains and general well-being. Social Indicators Research, 22(3), 255-276. https://doi.org/10.1007/BF00301101

Putney, S., \& Middleton, R. (1961). Dimensions and correlates of religious ideologies. Social Forces, 39(4), 285-290. https://doi.org/10.2307/2573423

Qiu, J., Shen, B., Zhao, M., Wang, Z., Xie, B., \& Xu, Y. (2020). A nationwide survey of psychological distress among Chinese people in the COVID-19 epidemic: Implications and policy recommendations. General Psychiatry, 33(2), e100213. https://doi.org/10.1136/gpsych2020-100213

Rababa, M., Hayajneh, A. A., \& Bani-Iss, W. (2021). Association of death anxiety with spiritual well-being and religious coping in older adults during the COVID-19 pandemic. Journal of Religion and Health, 60(1), 50-63. https://doi.org/10.1007/s10943-020-01129-X

Ramsay, J. E., Tong, E. M., Chowdhury, A., \& Ho, M. H. R. (2019). Teleological explanation and positive emotion serially mediate the effect of religion on well-being. Journal of Personality, 87(3), 676-689. https://doi.org/10.1111/jopy.12425

Richins, M. L., \& Dawson, S. (1992). A consumer values orientation for materialism and its measurement: Scale development and validation. Journal of Consumer Research, 19(3), 303-316. https://doi.org/10. 1086/209304

Rigoli, F. (2021). The link between COVID-19, anxiety, and religious beliefs in the United States and the United Kingdom. Journal of Religion and Health, 60(4), 2196-2208. https://doi.org/10.1007/ s10943-021-01296-5

Rinallo, D., Borghini, S., Bamossy, G., \& Kozinets, R. V. (2013b). When sacred objects go B®a(n)d. In R. Diego, L. M. Scott, \& P. Maclaran (Eds.), Consumption and spirituality (pp. 29-40). Routledge.

Rinallo, D., Scott, L. M., \& Maclaran, P. (2013a). Consumption and spirituality. Routledge.

Roof, W. C. (2001). The making of a quest culture. In Spiritual marketplace: Baby boomers and the remaking of American religion (pp. 46-76). Princeton University Press.

Rosmarin, D. H., Pargament, K. I., \& Mahoney, A. (2009). The role of religiousness in anxiety, depression, and happiness in a Jewish community sample: A preliminary investigation. Mental Health, Religion \& Culture, 12(2), 97-113. https://doi.org/10.1080/13674670802321933

Rote, S., Hill, T. D., \& Ellison, C. G. (2013). Religious attendance and loneliness in later life. The Gerontologist, 53(1), 39-50. https://doi.org/10.1093/geront/gns063 
Rudolph, C. W., Allan, B., Clarke, M., Hertel, G., Hirschi, A., Kunze, F., \& Zacher, H. (2020). Pandemics: Implications for research and practice in industrial and organizational psychology. Industrial and Organizational Psychology: Perspectives on Science and Practice. https://doi.org/10.31234/osf.io/ k8us2

Simkin, H. (2020). The centrality of events, religion, spirituality, and subjective well-being in Latin American Jewish immigrants in Israel. Frontiers in Psychology, 11, 576402. https://doi.org/10.3389/fpsyg. 2020.576402

Trenz, H. J., Heft, A., Vaughan, M., \& Pfetsch, B. (2021). Resilience of public spheres in a global health crisis. Javnost - The Public: Journal of the European Institute for Communication and Culture, 28(2), 111-128. https://doi.org/10.1080/13183222.2021.1919385

Trzebiński, J., Cabański, M., \& Czarnecka, J. Z. (2020). Reaction to the COVID-19 pandemic: The influence of meaning in life, life satisfaction, and assumptions on world orderliness and positivity. Journal of Loss and Trauma, 25(6-7), 544-557.

Uskul, A. K., \& Oyserman, D. (2010). When message-frame fits salient cultural-frame, messages feel more persuasive. Psychology and Health, 25(3), 321-337. https://doi.org/10.1080/08870440902759156

Van Bavel, J. J., Baicker, K., Boggio, P. S., Capraro, V., Cichocka, A., Cikara, M., \& Willer, R. (2020). Using social and behavioral science to support COVID-19 pandemic response. Nature Human Behavior, 4(5), 460-471. https://doi.org/10.1038/s41562-020-0884-Z

Villani, D., Sorgente, A., Iannello, P., \& Antonietti, A. (2019). The role of spirituality and religiosity in subjective well-being of individuals with different religious status. Frontiers in Psychology, 10, 1525. https://doi.org/10.3389/fpsyg.2019.01525

Weinstein, L., De Man, A., \& Almaguer, L. (1988). Purpose in life as a function of religious versus secular beliefs. Perceptual and Motor Skills, 67(1), 335-337. https://doi.org/10.2466/pms.1988.67.1.335

Worldometer (2021). COVID-19 coronavirus pandemic. Retrieved from https://www.worldometers.info/ coronavirus/?fbclid=IwAR2NtttOQotbU9wtW5EkNPKDdCxOInHFiMcHwyyzkUOw2Ecr8wa8x ZSXJOE

Zacher, H., \& Rudolph, C. W. (2021). Individual differences and changes in subjective wellbeing during the early stages of the COVID-19 pandemic. American Psychologist, 76(1), 50-62. https://doi.org/ 10.1037/amp0000702

Publisher's Note Springer Nature remains neutral with regard to jurisdictional claims in published maps and institutional affiliations.

Osnat Roth-Cohen is a Senior Lecturer in the School of Communication at Ariel University in Israel. Her research examines social media discourse and advertising and public relations impact on industry and society. Her work has been published in the Journal of Advertising, Public Relations Review, International Journal of Communication, Feminist Media Studies, and Current Issues in Tourism.

Sidharth Muralidharan is an Associate Professor in the Temerlin Advertising Institute at Southern Methodist University in Dallas, TX. His primary research interests are on cross-cultural studies and advertising's impact on mitigating social and environmental issues in India and abroad, while secondary research interests include social media and online advertising. His work has been published in Journal of Advertising; Journal of Advertising Research; International Journal of Advertising; International Journal of Consumer Studies; Asian Journal of Communication; Cyberpsychology, Behavior, and Social Networking; and Public Relations Review, among others.

Carrie La Ferle is the Marriott Endowed Professor of Ethics \& Culture in the Temerlin Advertising Institute at SMU. Dr. La Ferle holds a Ph.D. in advertising from the University of Texas at Austin, an M.A. in advertising from Michigan State University and a B.A. in sociology from the University of Western Ontario. Her research examines how culture (national, racial/ethnic, religious, etc.), impacts advertising and consumer behavior. She further examines ethical issues as they relate to culture and the impact of advertising on society. Dr. La Ferle's is author of Preaching and The Thirty-Second Commercial: Lessons from Advertising for the Pulpit and is widely published in prestigious journals such as Journal of Advertising, Journal of Advertising Research, International Journal of Advertising, and Journal of Business Research. 